\title{
Impact of Low-Carbohydrate Diet (LCD) and Obesity Management Program on Obese Patients
}

\author{
Rohit Sane ${ }^{1}$, Deepali Amin ${ }^{2}$, Vaishali Koli ${ }^{2}$, Rupali Kore ${ }^{3}$, Sneha Paranjpe ${ }^{2}$, Rahul Mandole ${ }^{1, *}$ \\ ${ }^{1}$ Department of Research and Development, Madhavbaug Cardiac Care Clinics and Hospitals, Mumbai, India \\ ${ }^{2}$ Madhavbaug Cardiac Care Clinics, Mumbai, India \\ ${ }^{3}$ Madhavbaug Cardiac Care Clinics, Sangli, India
}

Email address:

research.madhavbaug@gmail.com (R. Mandole)

${ }^{*}$ Corresponding author

\section{To cite this article:}

Rohit Sane, Deepali Amin, Vaishali Koli, Rupali Kore, Sneha Paranjpe, Rahul Mandole. Impact of Low-Carbohydrate Diet (LCD) and Obesity Management Program on Obese Patients. European Journal of Preventive Medicine. Vol. 7, No. 1, 2019, pp. 1-6.

doi: 10.11648/j.ejpm.20190701.11

Received: November 5, 2018; Accepted: November 27, 2018; Published: January 29, 2019

\begin{abstract}
The past two decades witnessed a rapid escalation in the prevalence of obesity. Ayurvedic physicians use a multifaceted strategy to treat obesity which includes a combination of Low-Carbohydrate Diet and Obesity Management Procedure. The present study was conducted to demonstrate the efficacy of low carbohydrate diet and the Ayurvedic obesity management procedure in reducing obesity. A retrospective observational study was conducted in Madhavbaug Clinics from September 2017 to March 2018. All patients with BMI $>30 \mathrm{~kg} / \mathrm{m}^{2}$ were included in the study. During the study, the patients received seven sessions of obesity management procedure which included a combination of Snehana / external oleation or massage, Swedana / passive heat therapy and Basti kadha. Simultaneously, patients were prescribed supervised low carbohydrate diet daily for 90 days. The primary efficacy end point was reduction in body weight while secondary end points included changes in abdominal girth, systolic and diastolic blood pressure, heart rate after 90-day follow-up as compared to baseline. A total of 48 patients were enrolled and after screening, 31 were included in the study. Most of the patients were middle aged (51.35 \pm 11.44 years) and females (65.8\%). The primary end-point used in the present study (body weight) decreased significantly from $89.87 \pm 18.58 \mathrm{~kg}$ on Day 1 to $82.01 \pm 20.55 \mathrm{~kg}$ on day 90 ( $\mathrm{p}<0.001)$. Such significant changes were also appreciable in the BMI, SBP, DBP, abdominal girth values measured on day 1 and day 90 respectively $(\mathrm{p}<0.001$ for all). The present study demonstrates that the combination of low carbohydrate diet and Ayurvedic obesity management procedures are effective in reducing obesity.
\end{abstract}

Keywords: Ayurvedic Obesity Management, Basti Kadha, Low Carbohydrate Diet, Obesity Snehana, Swedana

\section{Introduction}

Obesity is a major public health problem which results from an imbalance between energy intake and energy expenditure [1]. World health organization (WHO) defines an obese person as one with a BMI of 30 or more [2].

BMI was used as a criterion considering its strong correlation with cardiovascular mortality, diabetes and other comorbidities, mortality and disability. The worldwide obesity prevalence increased rapidly between 1980 and 2008 . In $2008,10 \%$ of men and $14 \%$ of women in the world were obese (BMI $\geq 30 \mathrm{~kg} / \mathrm{m}^{2}$ ), compared with $5 \%$ for men and $8 \%$ for women in 1980. An estimated 205 million men and 297 million women over the age of 20 were obese a total of more than half a billion adults worldwide.

India is not exempted from this pandemic and recent studies reveal that $12 \%$ of the entire population is overweight or obese [3]. According to the National Family Health Survey (NFHS-4), the prevalence of $\mathrm{BMI} \geq 25 \mathrm{~kg} / \mathrm{m}^{2}$ among Indian female is $20.7 \%$ and male is $18.6 \%$ [4]. Current socioeconomic development has shifted dietary patterns towards energy-dense junk foods which coupled associated sedentary lifestyle have contributed to the rise in overweight/obesity [5]. Obesity is closely associated with increased incidence of non-communicable diseases like diabetes, cardiovascular 
disease and hence appropriate management of obesity is a major public health challenge [3].

The current management protocol of obesity includes long term therapy with drugs like Phentermine, Orlistat, Sibutramine, Lorcaserin, Topiramate which have doubtful efficacy with serious safety concerns. Hence, the search for safe and effective alternative is of utmost importance in the management of obesity [6].

Ayurveda is an age old scientific medicinal system indigenous to India. Ayurveda means 'knowledge of life', which comprises of two Sanskrit words, Ayu (life) and Veda (knowledge or science). The principal aim of Ayurveda is to achieve equilibrium between the physiological and structural entities, which ultimately culminates in good health. Any disparity or unevenness because of external or internal factors may lead to disease development [7]. Ayurvedic treatment aims to restore the equilibrium through the utilization of different techniques, regimens, diet as well as medicines [8] Ancient Ayurvedic texts (Charakasamhita, Sushrutsamhita, Ashtang Sangraham, Ashtanga Hridayam) mention the clinical features and treatment of obesity (Sthaulyarog) indicating that the knowledge of the disease was present with the Ayurvedic physicians [9].

In our institute (Madhavbaug Hospital and clinics) the Ayurvedic physicians are using a multi-faceted obesity management protocol to treat obesity, which includes a lowcarbohydrate diet and combination of herbal treatment namely Snehana, Swedana, Basti Kadha. However, a literature search revealed that there is a dearth of published literature to demonstrate the efficacy of this treatment modality in obese patients. In this backdrop, the present study was conducted to demonstrate the efficacy of low carbohydrate diet and Ayurvedic obesity management program in treating obesity.

\section{Subject and Methods}

\subsection{Study Setting and Patient Selection}

A retrospective observational study was conducted in Madhavbaug Clinics, for a period of six months starting from September 2017 to March 2018 to address the study objective. All patients with a BMI greater than $30 \mathrm{~kg} / \mathrm{m}^{2}$ were considered eligible to participate in the study. The case definition of obesity was defined as patients with BMI $>30$ $\mathrm{kg} / \mathrm{m}^{2}$ [9]. Patients were recruited after obtaining written informed consent from them. The study was conducted according to the ethical principles mentioned in the Declaration of Helsinki, Good Clinical Practices, and applicable regulatory requirements.

\subsection{Study Procedure}

Patients with $\mathrm{BMI}>\mathrm{kg} / \mathrm{m}^{2}$ were considered to be eligible in the 90-day study after initial screening. The exclusion criteria were (i) severe cardiac, renal or hepatic disease (ii) pregnancy. On day 1 of the study, baseline clinical status of the patient was determined by measuring body weight, blood pressure, BMI, abdominal girth. Following this, low carbohydrate diet plan and obesity management procedure were started on the patient. A supervised daily diet plan with calorific value $800 \mathrm{kcal}$ was prescribed for the patient which consisted of $35 \%$ carbohydrate: $25 \%$ protein: $40 \%$ fat. The patient was asked to follow the diet plan for 90 days. In the study period of 90 days, the patient also received 7 sessions of obesity management procedure details of which are given below. The Obesity Management Program (OMP) is a combination of Panchakarma and allied therapies. OMP uses various decoctions and oils and constitutes of a 3-step procedure namely:

a. Snehana / external oleation or massage (25-30 minutes): Massage or external oleation (centripetal upper strokes on the body)

b. Swedana / passive heat therapy (15 -20 minutes): Dashmoola (group of ten herbs) steam of temperature not more than 40 was then passed steadily for 10-15 minutes. After the treatment, patients were asked to relax for 3-4 minutes.

c. Basti kadha: Medicated enema administered per-rectal, should be in body for $>15$ minutes for maximum absorption.

At the end of 90 days, the patients were examined and Body weight, BMI, SBP, DBP, AG were again measured and compared with the baseline.

The detailed schedule of Ayurveda obesity management procedure is described below in Table 1.

Table 1. Protocol of obesity management procedure.

\begin{tabular}{|c|c|c|c|}
\hline Step & Type of Therapy & Herbs used for therapy & Duration of therapy \\
\hline Snehana & $\begin{array}{l}\text { Massage or external oleation (centripetal upper } \\
\text { strokes on the body) }\end{array}$ & $\begin{array}{l}25 \mathrm{~g} \text { Azadirachta indica (neem leaves) extract } \\
\text { processed in } 100 \mathrm{ml} \text { sesame oil }\end{array}$ & $25-30$ minutes \\
\hline Swedana & Passive heat therapy to the body & $\begin{array}{l}\text { Dashmoola (group of ten herbal roots) with steam } \\
\text { at }<40 \text { degrees Celsius) }\end{array}$ & $\begin{array}{l}15-20 \text { minutes }+3-4 \text { minutes of } \\
\text { relaxation after procedure }\end{array}$ \\
\hline Basti kadha & $\begin{array}{l}\text { Drug administered per-rectal, should be in body } \\
\text { for }>15 \text { minutes for maximum absorption }\end{array}$ & $\begin{array}{l}\text { Mixture of } 10 \% \text { Kulattha (Dolichos biflorus), } 10 \% \\
\text { Nagavalli (Piper betle) and 5\% Meshashringi } \\
\text { (Gymnema sylvestre) }\end{array}$ & 10 minutes \\
\hline
\end{tabular}

\subsection{Statistical Analysis}

Data was entered in MS excel and analyzed using $\mathrm{R}$ Version 3.5.0 software. The data of only those patients who could complete the entire treatment of 90 days were considered for analysis. The primary efficacy end point was reduction in body weight while secondary end points include reduction in Abdominal Girth, SBP, DBP, HR after 90-day follow-up as compared to day 1 (baseline). Paired $\mathrm{T}$ test were 
used to test statistical significance for Primary and Secondary End Point We also calculated Correlation between weight \& BMI and weight and Abdominal Girth.

\section{Results}

During the study period, a total of 48 patients were enrolled and after screening 31 were included in the study.
All of them continued the treatment up to day 90 and were considered for analysis. There were no reports of serious adverse drug reaction in the study participants. Most of the enrolled patients were middle aged $(51.35 \pm 11.44$ years $)$ and female sex $(65.8 \%)$. The baseline BMI of the patients $(35.30$ $\pm 5.55)$ as measured on day 1 was well above WHO criteria of obesity. On day 1, the baseline abdominal girth, SBP; DBP were also measured and has been mentioned in Table 2 .

Table 2. Comparison of clinical parameters between baseline values and $90^{\text {th }}$ day.

\begin{tabular}{lllll}
\hline Variable $(\mathbf{n = 3 1})$ & Baseline (day 1) & After 90 days & Difference & \multicolumn{1}{c}{ P-value } \\
\hline Weight & $89.87 \pm 18.58$ & $82.01 \pm 20.55$ & 7.86 & $<0.001^{* * *}$ \\
BMI & $35.30 \pm 5.55$ & $32.11 \pm 5.98$ & 3.19 & $<0.001^{* *}$ \\
Abdominal Girth & $110.39 \pm 10.05$ & $103.92 \pm 11.97$ & 6.47 & $<.2$ \\
HR & $87.13 \pm 8.50$ & $81.93 \pm 8.66$ & $<0.001^{* * *}$ \\
\hline
\end{tabular}
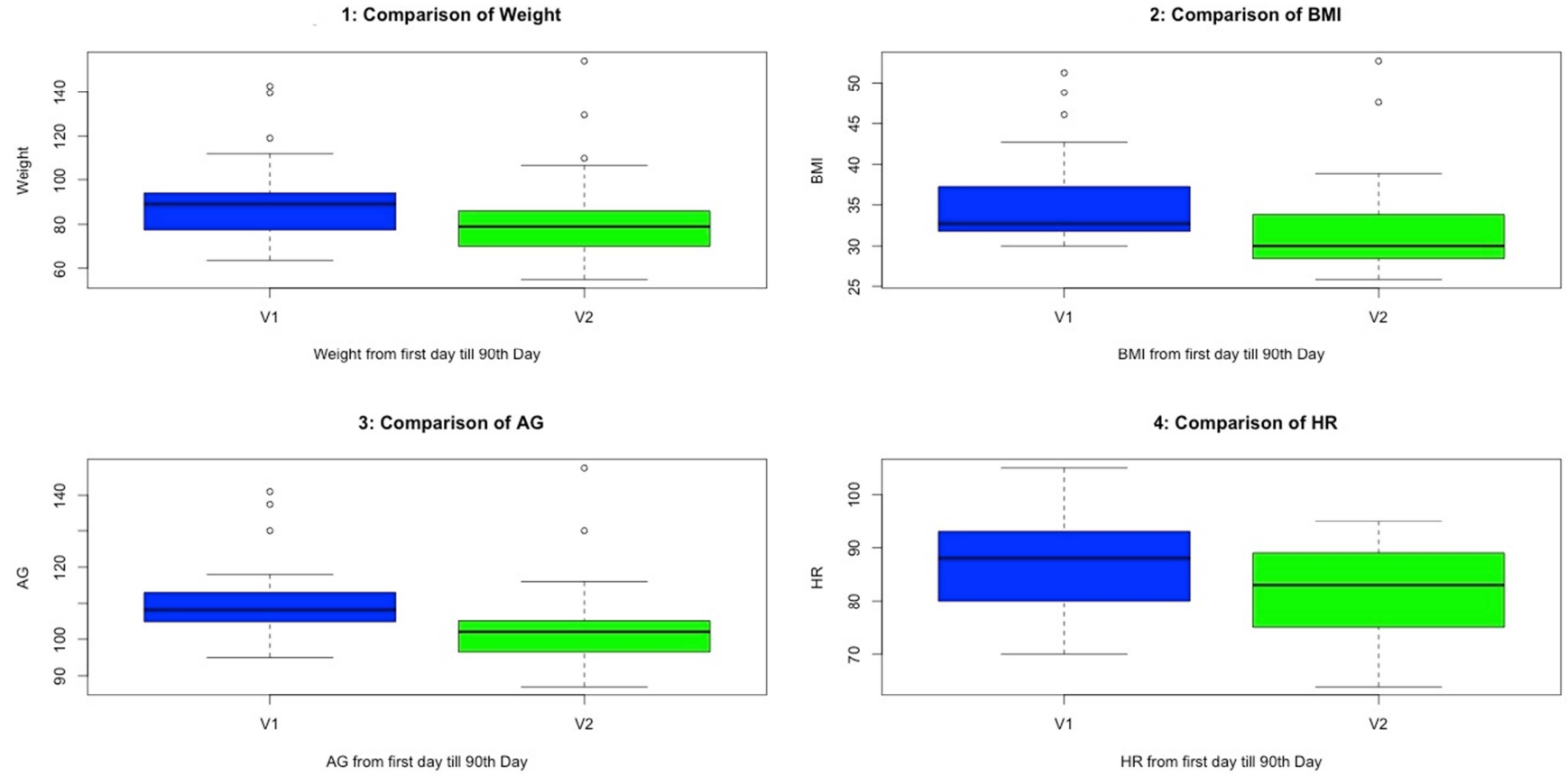

Figure 1. Comparison of Clinical Parameters between values and $90^{\text {th }}$ day.

Obesity is related to several chronic diseases like hypertension, cardiovascular disease, and diabetes mellitus and hence obese patients are prescribed medicines for these co-morbidities. In our study, the concomitant medications consumed by the patients on day 1 include Angiotensin receptor blockers, Calcium channel blockers, Statins, Diuretic, Beta-blockers, Sulfonylurea, Biguanides and Antiplatelet drugs. However, at the end of day 90, there was an appreciable decrease in the medication use by the patients, which has been shown in table 3 , figure 2 .

Table 3. Consumption of allopathic medicines on days 1 and 90.

\begin{tabular}{|c|c|c|c|c|}
\hline Drug class & Day 1 & $\%$ & Day 90 & $\%$ \\
\hline Angiotensin receptor blocker & 12 & 38.71 & 10 & 32.26 \\
\hline Statins & 7 & 22.58 & 6 & 19.35 \\
\hline Calcium channel blocker & 10 & 32.26 & 6 & 19.35 \\
\hline NSAID & 7 & 22.58 & 5 & 16.13 \\
\hline Diuretic & 6 & 19.35 & 5 & 16.13 \\
\hline Beta blocker & 5 & 16.13 & 5 & 16.13 \\
\hline Antiplatelet & 1 & 3.23 & 1 & 3.23 \\
\hline Sulfonylurea & 1 & 3.23 & 2 & 6.45 \\
\hline No medicine & 9 & 29.03 & 10 & 32.26 \\
\hline
\end{tabular}




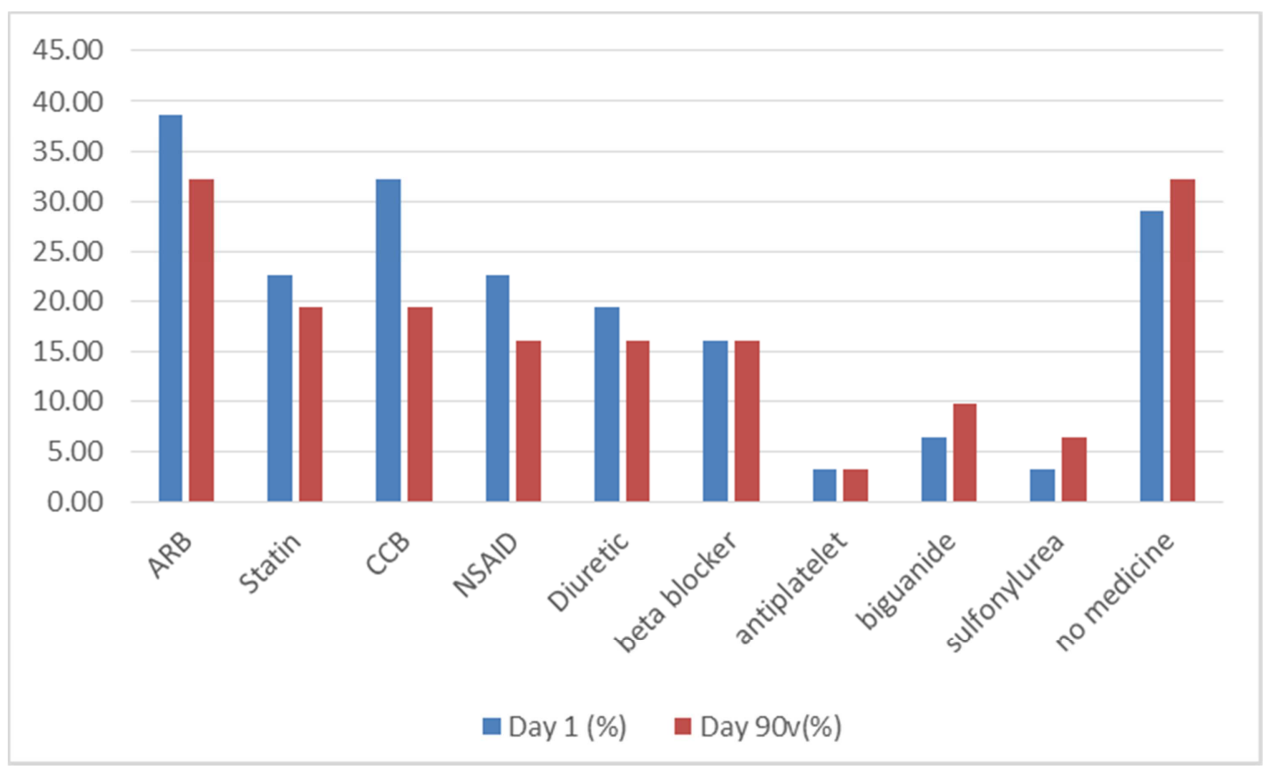

Figure 2. Consumption of allopathic medicines at days 1 and 90 days $(N=31)$.

The primary end-point used in the present study (body weight) decreased significantly from $89.87 \pm 18.58 \mathrm{~kg}$ on Day 1 to $82.01 \pm 20.55 \mathrm{~kg}$ at day $90(\mathrm{p}<0.001)$. Such significant changes were also appreciable in the BMI, abdominal girth values measured on day 1 and day 90 respectively $(\mathrm{p}<0.001)$ details of which is shown in table 2, figure 1 . We also explored the association between body weight and abdominal girth at day 1 and day 90. Abdominal girth and body weight showed perfect correlation both at day $1(\mathrm{r}=0.865)$ and at day $90(\mathrm{r}=0.91)$.

Table 4. Correlation between Weight and BMI/AG at $1^{\text {st }}$ day and $90^{\text {th }}$ Day.

\begin{tabular}{lll}
\hline Correlations table & \\
\hline 1 & Correlation between weight and BMI at Day 1 & 0.7955433 \\
2 & Correlation between weight and BMI at day 90 & 0.8792612 \\
3 & Correlation between weight and AG at Day 1 & 0.8659939 \\
4 & Correlation between weight and AG at day 90 & 0.9108754 \\
\hline
\end{tabular}

In addition, our study also revealed the efficacy of obesity management program in reducing Systolic Blood Pressure and Diastolic Blood Pressure in 23 patients, which is a new finding. In these 23 patients $(\mathrm{SBP}>130 \mathrm{mmHg}), \mathrm{SBP}$ was reduced by $22.17 \mathrm{mmHg}$ (from $144.78 \pm 13.77$ to $122.61 \pm$ 13.85; $\mathrm{p}<0.001$ ), DBP by $11.96 \mathrm{mmHg}$ (from $89.13 \pm 9.0$ to $77.17 \pm 8.12 ; \mathrm{p}<0.001$ ) and Weight by $8.16 \mathrm{Kg}$ (from $93.2 \pm$ 19.32 to $85.04 \pm 22.04 ; \mathrm{p}<0.001$ ), at the end of the 90 -day follow-up as compared to baseline.

\section{Discussion}

In Ayurvedic texts, obesity is referred to as "Medoroga" and is considered to be a disease of "Medadhatu" meaning a disorder of lipid metabolism. A variety of different types of obesity have been mentioned in the Ayurvedic classics along with the treatment for the same [8]. In the present study, we have combined low carbohydrate diet with certain Ayurvedic procedures (OMP) to treat obesity [8]. A critical review of published literature reveals that while some researchers have separately demonstrated the efficacy of diet in reducing obesity, some have explored the efficacy of Ayurvedic procedures only [11-15]. To our knowledge, the present study is the first one to demonstrate the combined effect of LCD and Ayurvedic procedure as a treatment modality to treat obesity.

In the present study, majority of the patients were of middle aged with age $(51.35 \pm 11.44$ years $)$. This is in concordance with earlier studies conducted in India by Auti SS (50-60 years), Paranjpe [11, 12]. The female outnumbered the males $(64.3 \%)$ as per the earlier study conducted by Auti SS (59.9\%), Paranjape [11, 12]

The current diet of India is rich in carbohydrates, with large quantities of rice in the coastal regions, chappatis in the interiors, and heavy consumption of bread all over. The widespread availability of fried and unhealthy fast food, adds empty calories to the diet. With Indians caught between these carbohydrate-rich diets, it is no wonder that obesity is on the rise in the country. Management of obesity requires reduction in calorie intake without compromising nutrition. In order to lose $0.5-1 \mathrm{~kg}$ per week, one needs to reduce calorie intake by 500-1000 kcal per day. It is noted that as per National Sample Survey Office's (NSSO) 2011-12 data on Nutritional Intake per capita calorie consumption is 2099 kilocalories per day in rural areas and 2058 kilocalories per day in urban areas while the average metabolic rate of person with sedentary lifestyle is 1400-1500 kcals [16, 17]. Hence creating a negative energy balance plays crucial role in weight loss. Negative calorie balance refers to reducing excess calorie intake and include required amount of nutrient which will help reduce desire weight. Ayurvedic texts mention that altered function of Agni or digestive power leads to production of Ama which cause derangement of Agni of fatty tissue and blocks the proper formation of further tissues [9, 15]. Accumulated fat alters movement of Vata which leads to increase in appetite. Person therefore eats more and the entire food is then converted into 
proper fat tissue. As per the line of treatment of obesity, the diet prescribed should be Apatarpana (no nourishing). The Apatarpana quality of food will help in the reduction of fat in the body $[9,15]$. This has also been reiterated in recent studies which indicate diets lower in carbohydrate have shown promise for weight loss when compared to typical reduced energy and fat diets $[13,14]$. In particular, multiple studies indicate that a low carbohydrate diet may produce greater weight loss than a traditional low fat diet over 6 months and may be comparable to a low fat diet over 12 months. In the present study also, low carbohydrate diet exerted a beneficial effect in reducing body weight, BMI.

In the present study, we have combined three Ayurvedic procedures in our obesity management procedure namely Snehana, Swedana and Basti kadha. Ayurvedic texts clearly mention role of each of these procedures in reducing obesity. Swedana is an important preparatory measure for the management of obesity $[9,15]$. It liquefies the vitiated Dosha which are spread through the body. Snehana is an important Poorvakarma which is administered prior to Samshodhana procedure. Because of application of Swedana, the vitiated Doshas are expelled out of the body $[9,15]$.

Basti has got an important place in Panchakarma therapy and is indicated for the treatment of obesity. It is having not only curative action but also preventive actions. The Basti by its virtue of its Lekhana property reduces the Meda and simultaneously pacifies the Vata $[9,11,15]$. This may be attributable to the lipid lowering properties of the herbs used in Basti namely Kulattha (Dolichos biflorus), Nagavalli (Piper betle and Meshashringi (Gymnema sylvestre) [18]. Decreasing the formation of new adipose tissue and formation of fat reserves through inhibition of differentiation of pre-adipocytes into mature adipocytes is considered as an effective strategy to control adipogenesis mediated diseases, especially obesity [19]. Modulation of adipogenesis and lipolysis in humans may thus lead to a reduction in the burden of obesity. Extracts from kulattha (Dolichos biflorus), Nagavalli (Piper betle and Meshashringi (Gymnema sylvestre) exhibited potent antiadipogenic and lipolysis promoting activities in earlier studies [19]. In an earlier clinical study conducted by Auti SS (2013), Lekhana Basti was administered to study participants which reduced body weight of patients by $3.34 \%$ and BMI by $3.36 \%$ as compared to baseline [11].

\section{Conclusion}

The present study demonstrates that combination of low carbohydrate diet and Ayurvedic obesity management procedures acted in synergy to cause significant reduction in body weight, BMI, abdominal girth, without any adverse effect. Further studies with longer duration can offer more meaningful evidence on efficacy of this treatment modality.

\section{Acknowledgements}

We are thankful to Dr. Jagdish Hiremath, Chair Professor of Madhavbaug Institute of Preventive Cardiology for guiding us through this concept and Data Analysis

\section{References}

[1] Mehrabani J, Ganjifar ZK. Overweight and Obesity: A Brief Challenge on Prevalence, Complications and Physical Activity among Men and Women. MOJ Women Health 2018; 7 (1): 00161.

[2] World Health Organisation. Fact sheet on obesity and overweight. Download from http://www.who.int/en/newsroom/fact-sheets/detail/obesity-and-overweight.(Last accessed August 16, 2018).

[3] Siddiqui MZ, Donato R. Overweight and obesity in India: policy issues from an exploratory multi-level analysis. Health Policy Plan. 2016; 31: 582-91.

[4] National Family Health Survey - 4. Fact Sheet. 2015-16. Available at http://www.rchiips.org/ NFHS/pdf/NFHS4/India.pdf. Accessed on 15 August 2018).

[5] Misra A Shrivastava U. Obesity and dyslipidemia in South Asians. Nutrients 2013; 5: 2708-33.

[6] Wyatt HR. Update on treatment strategies for obesity. J Clin Endocrinol Metab. 2013; 98 (4): 1299-1306.

[7] Department of Ayurveda, Siddha, Unani and Homeopathy (AYUSH). Ayush in India. Department of Ayurveda, Siddha, Unani and Homeopathy (AYUSH), Ministry of Health \& Family Welfare, Govt of India; 2007.

[8] S. P. Vinjamury, M. Vinjamury, S. Sucharitakul, I. Ziegler. Panchakarma: ayurvedic detoxification and allied therapiesis there any evidence? Evidence-based practice in complementary and alternative medicine, Springer, Berlin, Heidelberg 2012, 113-137.

[9] Sinha K, Gaikwad S, Prabhakar M, Lohith BA. Critical review on role of panchakarma in sthaulya with special reference to obesity. Int. J. Res. Ayurveda Pharm. 2017; 8 (6): 4-7.

[10] http://www.philspenonlinejournal.com/01_BMI_Asian_WHO _criteria_0005.pdf (accessed on 16.th August 2018).

[11] Auti SS, Thakar AB, Shukla VJ, Ravishankar B. Assessment of Lekhana Basti in the management of hyperlipidemia. Ayu 2013; 34: 339-45.

[12] Paranjpe P, Patki P, and Patwardhan B (1990) Ayurvedic treatment of obesity: a randomized double-blind, placebocontrolled clinical trial. J Ethnopharmacol 29: 1-11.

[13] Brehm BJ, Seeley RJ, Daniels SR, D'Alessio DA: A randomized trial comparing a very low carbohydrate diet and a calorie-restricted low fat diet on body weight and cardiovascular risk factors in healthy women. J Clin Endocrinol Metab. 2003, 88 (4): 1617-1623. 10.1210/jc.2002021480 .

[14] Foster GD, Wyatt HR, Hill JO, McGuckin BG, Brill C, Mohammed BS, Szapary PO, Rader DJ, Edman JS, Klein S: A randomized trial of a low-carbohydrate diet for obesity. N Engl J Med. 2003, 348 (21): 2082-2090.

[15] Swati. S. Deshpande Et Al: Panchakarma Approach To Sthoulya. International Ayurvedic Medical Journal 2017. Available from: http://www.iamj.in/posts/images/upload/3534_3539.pdf 
[16] Annual Report. National Sample Survey Office. Downloaded from: http://www.mospi.gov.in/national-sample-survey-officensso (Last accessed 16 th August 2018).

[17] Narasinga Rao BS: Nutrient requirement and safe dietary intake for Indians. NFI Bull 31: 1-5, 2010.

[18] Vagbhata, Ashtanga Samgraha, Kalpasthana. Basti kalpa
Adhyaya, 5/68. In: Vaidya Anant Athavale., editor. 8th edition. Pune: Shrimad Atreya Prakashana; 1980. p. 30.

[19] Sengupta K, Mishra A T, Rao M K, Sarma K V, Krishnaraju A V, Trimurtulu G. Efficacy of an herbal formulation LI10903F containing Dolichos biflorus and Piper betle extracts on weight management. Lipids Health Dis. 2012; 11: 176. 